\title{
Landscape Valuation of Environmental Amenities throughout the Application of Direct and Indirect Methods
}

\section{Luís Loures ${ }^{1,2, *}$, Ana Loures ${ }^{2, \dagger}$, José Nunes ${ }^{2,3, \dagger}$ and Thomas Panagopoulos ${ }^{1, \dagger}$}

1 Centre for Spatial and Organizational Dynamics (CIEO), Ed. 8 Campus de Gambelas, 8005-139 Faro, Portugal; E-Mail: tpanago@ualg.pt

2 Instituto Politécnico de Portalegre (IPP), Praça do Mun. Apartado 84, 7301-901 Portalegre, Portugal; E-Mails: alloures@esaelvas.pt (A.L.); ratonunes@esaelvas.pt (J.N.)

3 Unidade de Investigação em Química Ambiental (UIQA), Instituto Superior de Agronomia, Tapada da Ajuda, 1349-017 Lisboa, Portugal

$\dagger$ These authors contributed equally to this work.

* Author to whom correspondence should be addressed; E-Mail: 1cloures@esaelvas.pt; Tel.: +351-268-628-528.

Academic Editor: Marc A. Rosen

Received: 13 October 2014 / Accepted: 4 January 2015 / Published: 12 January 2015

\begin{abstract}
Landscape design, construction and management should no longer be the result of superficial approaches based exclusively on designers' and planners' ideas. This research starts with the assumption that the aesthetic component constitutes an essential attribute for better understanding and evaluating landscapes. This study analyzes the aesthetic quality and economic valuation of the Lower Guadiana river landscape, through the application of direct and indirect landscape evaluation methods. In order to gauge not only experts' opinion, it is supported by the application of public participation techniques about the opinion and perceptions of the site visitors/users. The present research considered the analysis of six landscape subunits regarding landscape quality, fragility and visual absorption capacity. The obtained results showed that there are significant differences between the perceptions of the general public and experts' analysis. Touristic Complexes and Golf Courses had high visual quality, while Agricultural and Production Areas had high visual fragility. Moreover, the performed analysis made clear that the combined use of landscape assessment methods is suited to this type of study, since it enables quantifying the value of existence, management and maintenance of a particular environmental assets and/or services.
\end{abstract}


Keywords: aesthetic analysis; lower guadiana; riverscape; public participation; economic valuation

\section{Introduction}

There is more to landscape than what we see. An observer's knowledge, the processes that led to its formation, and the ways it can be influenced are becoming ever more important in landscape assessment practices [1]. Thus, the analysis of the evolution of the term "landscape" represents a crucial starting point in studies in which it is the central element. The concept has acquired multiple definitions according to the spectrum analysis and the field in which it is analyzed. According to Telles [2], one could say that "landscape is everything", because although, over the years, some authors have presented various types and concepts of landscape, they are merely definitions of analytical value, based on a whole in which the human being is an integral part, comprising a specific identity, and has been evaluated basically considering aesthetic principles.

Aesthetics is a concept developed by Western civilization, and has been a subject of debate for philosophers and artists from the time of ancient Greece, and more recently for architects, urban and environmental managers and even policy makers [3]. Although artists were the first to begin to reconceive this concept, seeking a type of formal assimilation for everyday use, architects were the ones that attempted to define it, using a method capable of reacting and integrating aesthetics in man's life and in the spaces that protect him [4]. For this reason, many landscape architects and other environmental specialists have begun to look at landscape not only as a scenery in which to intervene, inserting an indefinite variety of objects, but as a tool through which to design and manipulate complex realities. This fact is noted in the long tradition of landscape ecology and landscape planning that for several decades has holistically considered different landscape functions or services (including the aesthetic one) in a very sensitive way, carefully integrating the analysis of these functions, as well as the potential impacts of landscape change, in the development of propositions for future landscape development, as presented by several different authors [5-8].

Additionally, it is increasingly acknowledged that understanding the aesthetic character of any landscape, as well as a design process that facilitates a fair representation of existing landscape attributes, is paramount for success [9]. These facts turned landscape into something different, an entity sensitive to different transformations, which records the movement and events that cross it, and which is possible to evaluate and attribute a specific economic and/or use value that reinforces its existence and need for protection.

Considering these assumptions, this research aims to assess the aesthetics and the economic value of the Lower Guadiana river landscape, located in the Mediterranean region in southern Portugal, while comparing the application of direct methods of landscape assessment (based in the analysis and description of a set of landscape features, combined in a certain way in order to obtain a specific value which represents its scenic/aesthetic quality) and indirect methods of landscape assessment (that enable forming the definition of the use value of a specific environmental amenity, attributing a determined economic value to the indirect use of a specific environmental amenity or service). 
In parallel, there is a set of secondary objectives, such as: To assess the parameters of aesthetic appreciation of the landscape, with greater significance and prevalence relative to the intervention area considering the different landscape subunits identified in the study area; to identify patterns of public preference; to verify the relationship between the different techniques for landscape quality evaluation; and to assess the value that people attach to the river. In this regard, it was considered also the identification and analysis of several local and regional information sources regarding the main strengths, weaknesses, opportunities and threats of the study area in order to develop a SWOT analysis, which, coupled with the data obtained throughout the application of the direct and indirect landscape assessment methods, will strengthen the results obtained by this research.

\section{Landscape Assessment Methods-A Brief Review}

From the numerous classifications of landscape assessment techniques that have been tested and analyzed in recent years, the method of landscape evaluation subdivided into direct and indirect methods as described by Panagopoulos [10], is the one that better suits the present research.

In this regard, the proposed subdivision was used as a starting point, taking into account not only the overall objectives of the research, but also the ideas according to which the methods to carry out the evaluation of landscape aesthetic qualities should be based on, and mixed methods of evaluation, such as specialist or behavioral type analyzes [11]. However, even if it is recognized that expert approach techniques clearly dominate environmental management practices, while the perception-based approach is more commonly used in research, the combined use of direct and indirect landscape evaluation methods might create new standards and protocols for techniques of objectively estimating public perception of aesthetic quality that might enhance landscape planning and management objectivity.

\subsection{Direct Methods of Landscape Assessment}

The methodologies for direct landscape evaluation consist in analyzing and describing a set of landscape features, combined in a certain way in order to obtain a total value, which represents the total scenic quality, obtained by the sum of the parts [12]. Regardless of the skills and knowledge of each observer, it is commonly accepted that landscape quality derives from the interaction between their biophysical characteristics, the perceptive processes and the experiences and knowledge of the observer [13].

\subsubsection{Visual Quality Assessment (VQA) and Landscape Visual Fragility (LVF)}

Once the issues inherent to landscape analysis have been introduced, it is important to define VQA and LVF. Generally, while landscape quality is based on the capacity that a specific landscape has, or does not have, to be impaired or destroyed, i.e., landscape's inherent ability to retain its essential qualities and structure [14], fragility is considered the degree or level of susceptibility that a certain landscape has towards transformation as a result of an alteration to the original. In other words, it may be defined as the degree of deterioration that a certain landscape would experience with the introduction of other uses or functions [14]. Unlike quality, fragility depends directly on the type of activity that will be developed in a given landscape [13-15]. 
For this reason, the factors/parameters that are generally considered in VQA and LVF are not the same. Ayala et al. [14] defines the following as relevant for the analysis of VQA: Vegetation, land use, slope, physiography, size and shape of the visual basin, as well as the distance to roads, paths, and urban centers. Regarding the analysis of the LVF, the same author considers physical geography, vegetation and land use, presence of water, and degree of humanization, as the necessary analysis parameters.

\subsubsection{Visual Absorption Capability (VAC)}

VAC is considered by Canter [13] as the last component of visual management systems, which allows the definition of the magnitude of visual impacts on the landscape and/or the ability that a particular landscape has to absorb them. According to Vargues [16], the method used for determining the VAC is calculated according to the magnitude of the impact that a specific project or activity will have on a given landscape, through the relationship of physical factors, perceptive factors, and variables significantly inherent to the existing visual quality (shape, line, color and texture) and the proposed activity (scale, setting, duration, frequency, etc.).

This analysis is highly subjective and dependent on the observer. According to Burley [15], the following factors must be considered in VAC analysis: slope; vegetation; and the observer distance, for which three categories of space inherent in different planes are considered - the foreground, middle ground and background - taking into account that when the distance from the observer increases, so does the visual absorption capability.

\subsubsection{Psychophysical Preference Models}

Psychophysical preference models constitute a landscape evaluation method used quite often [10], whose main advantage is the ability to create new protocols for estimating objectively the public preferences and opinions regarding the aesthetic quality of a certain landscape.

In this approach, public preference, obtained through processes associated with direct and indirect participation surveys, is combined with the characteristics of the landscape in order to obtain balanced information between the two components, with the weights of each factor and the variables, and is generally estimated through assessments of public preference.

\subsection{Indirect Methods of Landscape Assessment}

According to Mazure and Burley [17], integrated landscape assessments, considering aesthetic, economic and ecological variables, showed that the obtained results are not independent and that there is a direct relationship between the different components and co-analysis. Considering those principles, several economists have focused on the development of methodologies for indirect assessment of the landscape. In these methods, the demand and use value of a specific environmental amenity is used to assess the quality of the landscape, giving it an economic value to produce relevant information for the development of effective management policies. Among the existing methods of economic valuation, two deserve special mention, the "travel-cost" method and contingent valuation method. 


\subsection{1. "Travel Cost” Method}

According to Leite and Jacoski [18], the travel cost method is one of the most used indirect methods of landscape assessment that can be used to appraise recreation and leisure activities. This method may be defined according to Oesten [19] as an evaluation whereby the value of an indirect benefit is attributed based on the average cost spent by a given set of individuals to reach a particular good or service without defined market cost. Still, this method works with some assumptions [20] which may be considered a limitation of the method: (I) it is considered that each person is traveling alone, even if it was a group journey; (II) it considers that the visit or travel to the amenity in question was the sole reason for the trip, even if there were others. However, regardless of the limitations that are inherent in the direct application of the method, it is generally recognized that it enables the definition of a demand curve for a particular environmental/recreational amenity, where the number of visits is a function not only of travel costs, but also of other socio-economic variables [18,21], thus defining the possible added value to the enjoyment of the natural resource/amenity.

\subsubsection{Contingent Valuation Techniques}

The contingent valuation techniques consist of interviews with certain individuals in order to assess the valuation of a specific property using a hypothetical market [22]. In general, the use of contingent valuation techniques relates to the use of questionnaires for public participation to a particular sample of the users of a given amenity or environmental resource, aiming to collect information on the use value, the option value and the value of existence of that amenity. This value refers to the possibility of passive use of the amenity [22]. Use value, option value and existence value mean the inherent willingness of each individual to pay in order to use a particular amenity in the present, to pay for the possibility to use it in the future, or even to pay simply to ensure its existence [23].

\section{Materials and Methods}

As presented in Figure 1, this investigation is divided into two complementary components: the first one based mainly on literature review and the second one is composed of the analysis of a specific study area. The developed methodology was based on the following steps: analysis of the state of the art and definition of the study area. After developing the literature review and the biophysical characterization and analysis of the study area, we started to identify and collect a set of complementary information regarding the main strengths, weaknesses, opportunities and threats in order to develop a SWOT analysis for the study area. This information, though not directly linked with the results obtained throughout the application of the landscape evaluation methods, enables us to understand, generally, people's perceptions towards the study area and to prepare the questionnaire.

After this first analysis and characterization, we moved to the visual analysis of the landscape, considering first the definition of the visual basin, applying the methods used in several previous studies [24-28] and then the classification of the different landscape subunits identified in the study area, according to specific criteria of relative homogeneity. The limit of the study area was obtained throughout the intersection of different biophysical landscape attributes, orthophotomap analysis and in situ observations, in order to increase the objectivity of the analysis. Subsequently, the identified 
subunits were characterized according to several different parameters in order to acquire a consistent description of each landscape subunit. After this stage, we defined specific viewpoints for each landscape subunit in which VQA and LVF as well as VAC were determined and analyzed.

At this stage, and since landscape evaluation processes are relatively dependent on the observer - a fact that is considered to be of particular relevance for this type of study-in order to decrease the subjectivity we decided to develop multiple analyzes. So, we invited seven specialists in scientific domains related to landscape and environment, following the methodology used by Loures et al. [29], to evaluate each of the factors mentioned above, using both the variables defined in the predetermined questionnaire and the ones indicated in the performed literature review. The data obtained from this questionnaire were entered into Microsoft Office Excel 2007, where means were calculated from the values assigned to each of the landscape subunits, and for each factor in order to obtain accurate values of VQA, LFV and the VAC for the different landscape subunits.

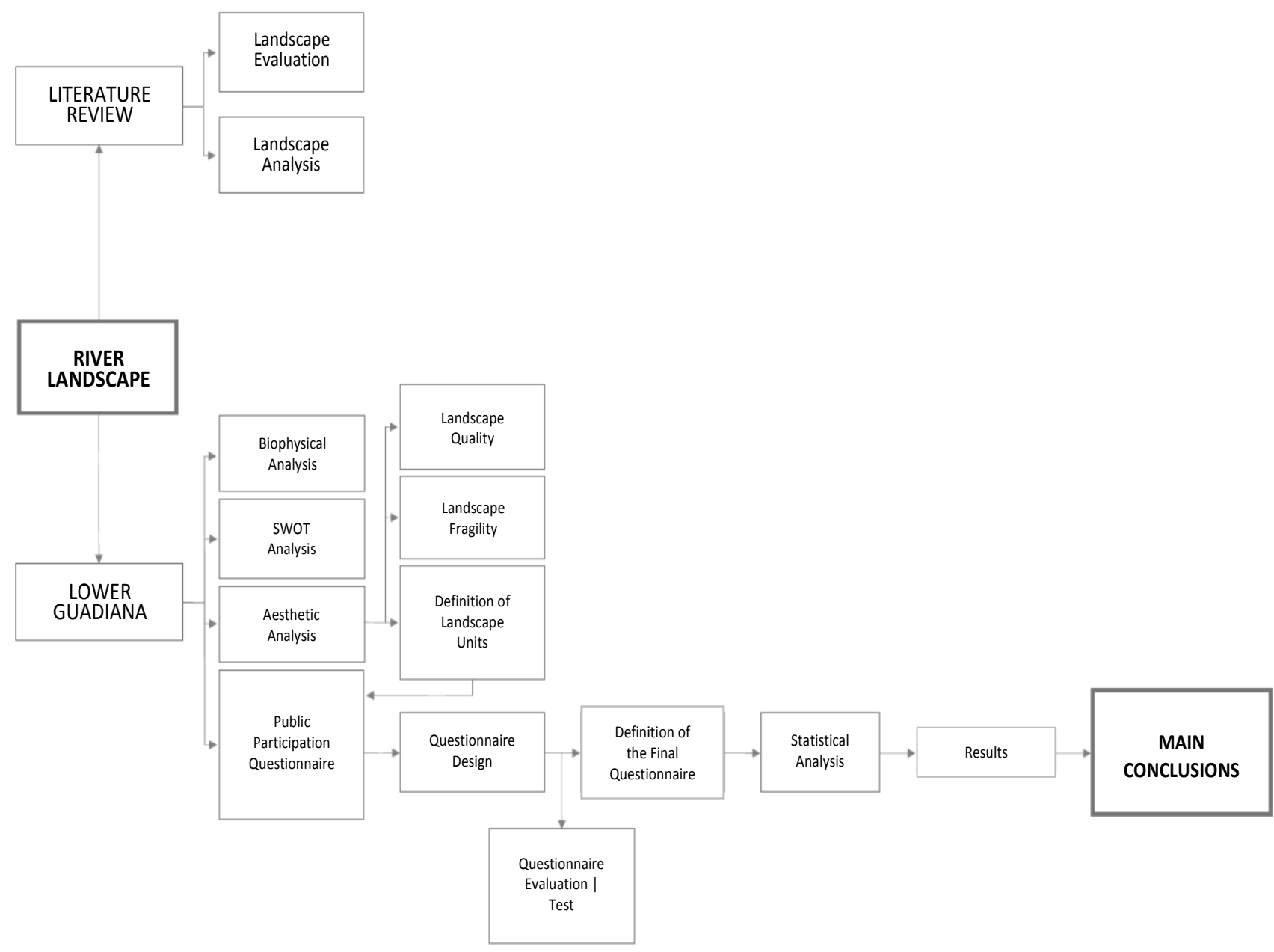

Figure 1. Methodological Framework.

Considering the objective to obtain people's perceptions towards the study area, a public participation questionnaire was developed as well (Figure 2). This questionnaire was composed of 10 questions, nine of which were closed, in order to limit the variability of the responses and to decrease the complexity of the questionnaire and to enable the acquisition of public opinion (visitors/users of the Lower Guadiana River landscape) both regarding to the aesthetic quality and to the economic valuation of this landscape. 
Regarding the questionnaire, it was decided that it should be delivered to 250 visitors/respondents, of which we should receive at least 100 questionnaires completely filled and validated during four different boat trips/visits (if this amount was not reached, more trips should be planned till we obtained 100 validated questionnaires). The used method was of direct interview; however, considering that it was a trip of recreational/leisure nature, the questionnaires were delivered to visitors at the entrance of the boat where a brief introduction/explanation of the research framework and objectives was performed. At the end of the trip, the respondents who decided to complete the questionnaire delivered them at the boat exit. Once we collected the necessary amount of questionnaires, we proceeded to the statistical analysis, which subsequently led to the results. The obtained data were inserted and organized in Microsoft Office Excel 2007, and then into the Statistical Package for Social Sciences (SPSS). The answers to the open question, before being inserted into the database, were grouped into classes.

Although the analysis of the questionnaire was essentially based on the descriptive statistics, inferential statistical analysis was also developed. At this level, chi-square test was used to assess whether, according to public preference, whether or not there is a significant relationship between the different landscape subunits [30,31]. Finally, the obtained results were discussed and conclusions were drawn.

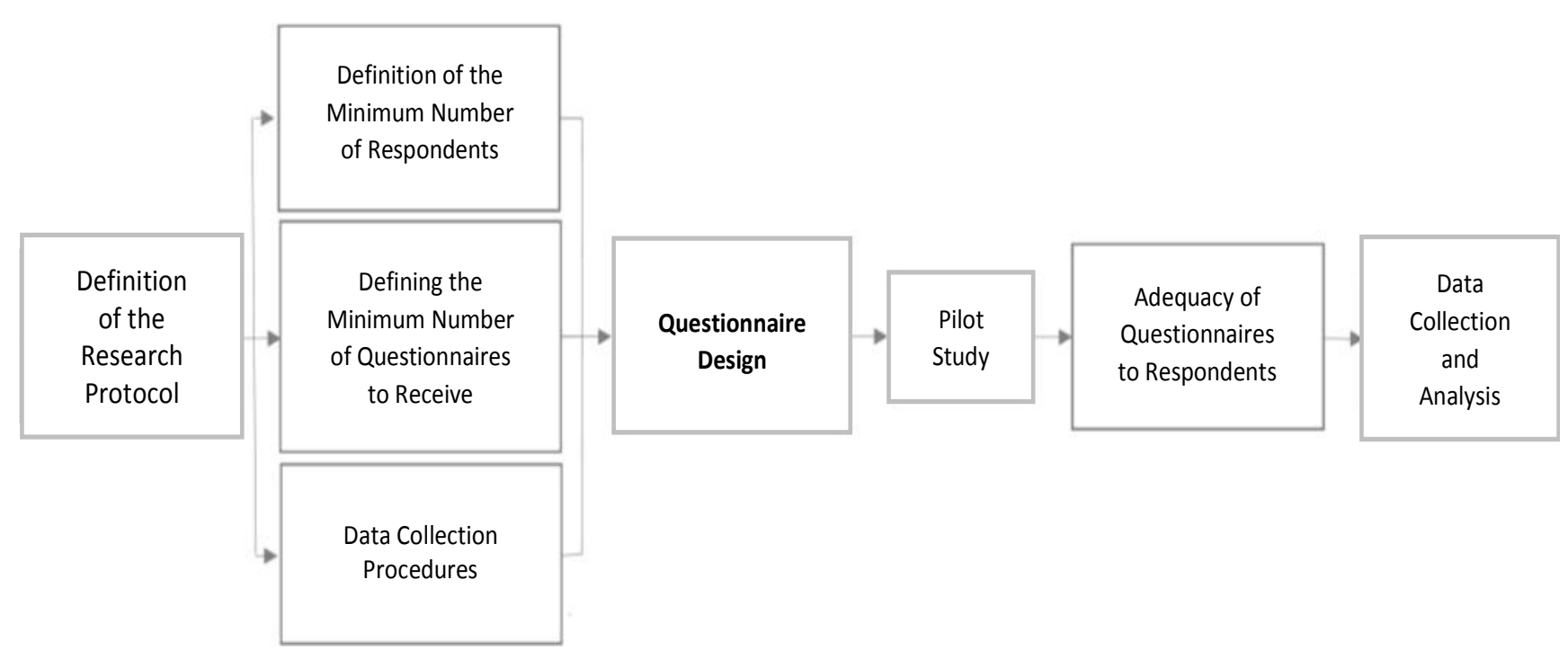

Figure 2. Questionnaire application Framework.

\section{Study Area}

The study area is located on the right bank of the river Guadiana (Figure 3), covering the municipalities of Vila Real de Santo António, Castro Marim and Alcoutim-Area known as Baixo Guadiana (Figure 4). The climate of this region is temperate Mediterranean, with mild and short winters and long, hot and dry summers, with very high insolation. Relative air humidity values are considerably high, especially in the winter months, due to the proximity to the river and to the sea [32].

The study area presents significant differences between the different geographic units that compose it (coastline, barrocal and mountain areas) noted not only in physiographic terms, but also in terms of population density, services, routes, tourism (the main driver of the local economy), etc. 


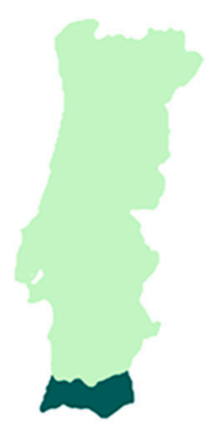

Portugal

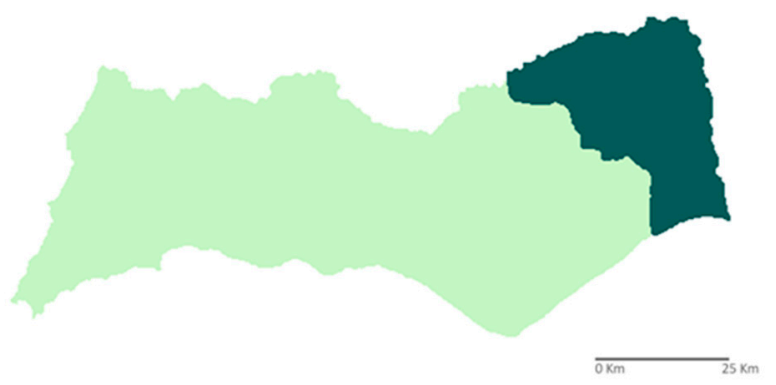

Algarve

Figure 3. The study area at the region of Algarve, Portugal.

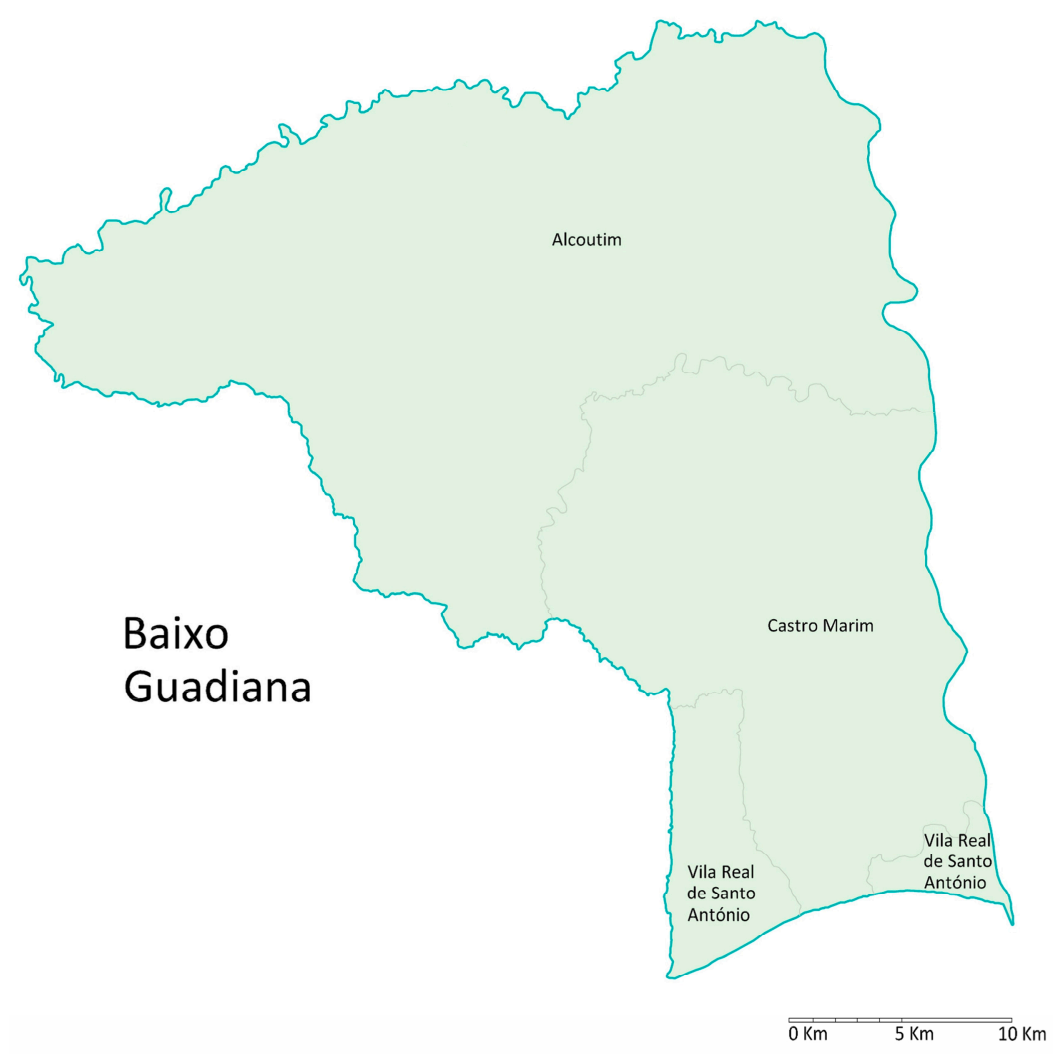

Figure 4. Different municipalities present in the study area-Baixo Guadiana, Portugal.

For this investigation, with the aid of geographical information systems, we studied several different landscape attributes such as slope (most of this region has gentle slopes, although it also presents steep and very steep slopes, associated with the mountainous region-Serra do Caldeirão); sun exposure (showed that it corresponds to an area of high temperatures since it is mainly exposed south, southwest and west), and land use that according to the information available in the regional master plan, PROTAL, and on several field visits to the study area showed that most of the Lower Guadiana area is occupied by forest and agricultural areas (some of them abandoned).

\subsection{SWOT Analysis}

As it was mentioned before, this landscape is very diverse (the Lower Guadiana region presents differences between the coast, barrocal and the mountainous region) not only in biophysical aspects, but 
also regarding socio-economic and cultural ones. For this reason, it was essential to develop a summarized SWOT analysis, so that we can better understand these differences and the way they influence people's perceptions towards the region. The developed analysis, based on the information obtained both at local and regional level [33], showed that the main strengths, weaknesses, opportunities and threats, inherent to this landscape are of utmost importance for the performed landscape assessment, since they highlight the existence of relevant differences across the study area.

\section{Strengths}

- Emergence of new activities within the touristic-leisure cluster in low-density areas, namely golf;

- Growth in the supply of accommodation in rural areas;

- Natural conditions for senior tourism, sports and health/environmental activities;

- Strengthening of planning instruments for landscape and environmental protection;

- Existence of natural resources conducive to the activities of agriculture and fisheries;

- Existence of natural conditions that favor the use of renewable energies;

- Development of pilot projects exploring alternative energy and new uses for traditional resources;

- Amenity of climatic conditions and high extent of protected areas of high biodiversity.

\section{Weaknesses}

- Small enterprises in the agricultural and fisheries sector;

- Vulnerability of the tourism sector to external factors;

- High seasonality of the tourism product that is based on the binomial sun-beach;

- Contamination of water supplies, due to the intensive use of pesticides and fertilizers and the lack of treatment of some wastewater;

- High urban concentration along the coast, while the interior faces progressive desertification;

- Crisis of the sustainability model of low-density areas;

- Weak provision of public transport services, railway regional network and lack of strategy towards the implementation of intermodal systems;

- Increasing intra-regional disparities in the distribution of population and urbanization.

\section{Opportunities}

- Available space for the creation of new companies based on entrepreneurship and the relationship between research areas with market potential;

- Environmental certification in tourism to promote a regional image of environmentally friendly;

- Existence of several undergoing projects regarding the revitalization of low-density areas;

- New employment opportunities in areas associated to services and to intangible investment;

- Increasing demand for tourism products associated with the environment, the river and the sea;

- Recovery of urban and natural areas attractive to people looking for high life quality.

\section{Threats}

- Competition for tourism with the Andalusia market;

- Reduction of natural resources, in particular those linked to the fisheries sector;

- Increased population and urban pressure on natural ecosystems, especially in coastal areas;

- Increasing desertification of soil and reduction of water reserves; 
- Loss of international attractiveness of the destination Algarve;

- Lack of rail link to Andalusia;

- Worsening the imbalance between the coastal clusters of smaller dimension and rural villages.

\subsection{Aesthetic and Visual Analysis of the Study Area}

The visual basin of the study area was measured using ArcGIS 3D Analyst 9.2, which enabled the production of a digital terrain model (DTM) from digitized counter lines. However, due to vegetation and construction, the actually visible area from the river was smaller than that calculated by the Digital Terrain Model (DTM). In this sense, the visible area was adjusted manually in situ on an ortofotomapa, considering the area, which could actually be seen (Figure 5).

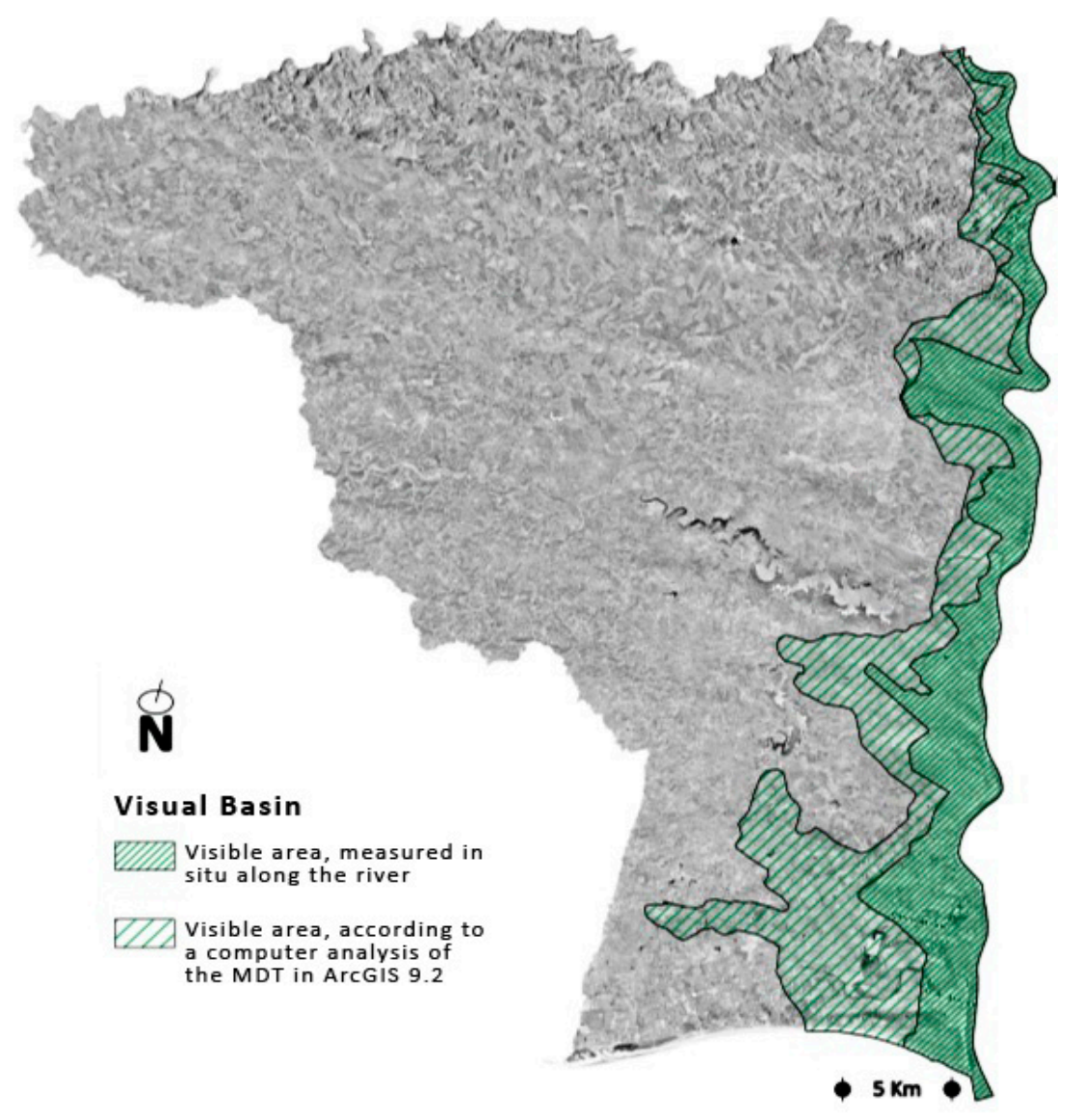

Figure 5. Visual basin calculated in ArcGIS versus visual basin adjusted after in situ observation.

After estimating the visual basin, the different landscape subunits present in the study area were identified according to relative homogeneity criteria as defined by Abreu et al. [34]. At this level, it should be noted that the delimitation leads to the establishment of an internal coherence, according to which subunits might be easily identified and characterized.

Thus, the following six landscape subunits were identified: Salinas; Wetlands and Marshland; Agricultural and Production areas; Uncultivated areas; Golf and Touristic Complex; and Urban Areas (Figure 6). For each of the identified landscape subunits, the VQA, LVF and VAC were analyzed using the collaboration of specialists, and the visitors who completed the questionnaire during a boat trip along the Guadiana River. 
Along the route, several stops were made at strategic observation points, which are marked in Figure 7 , in order to allow for a better analysis of the aforementioned landscape subunits.

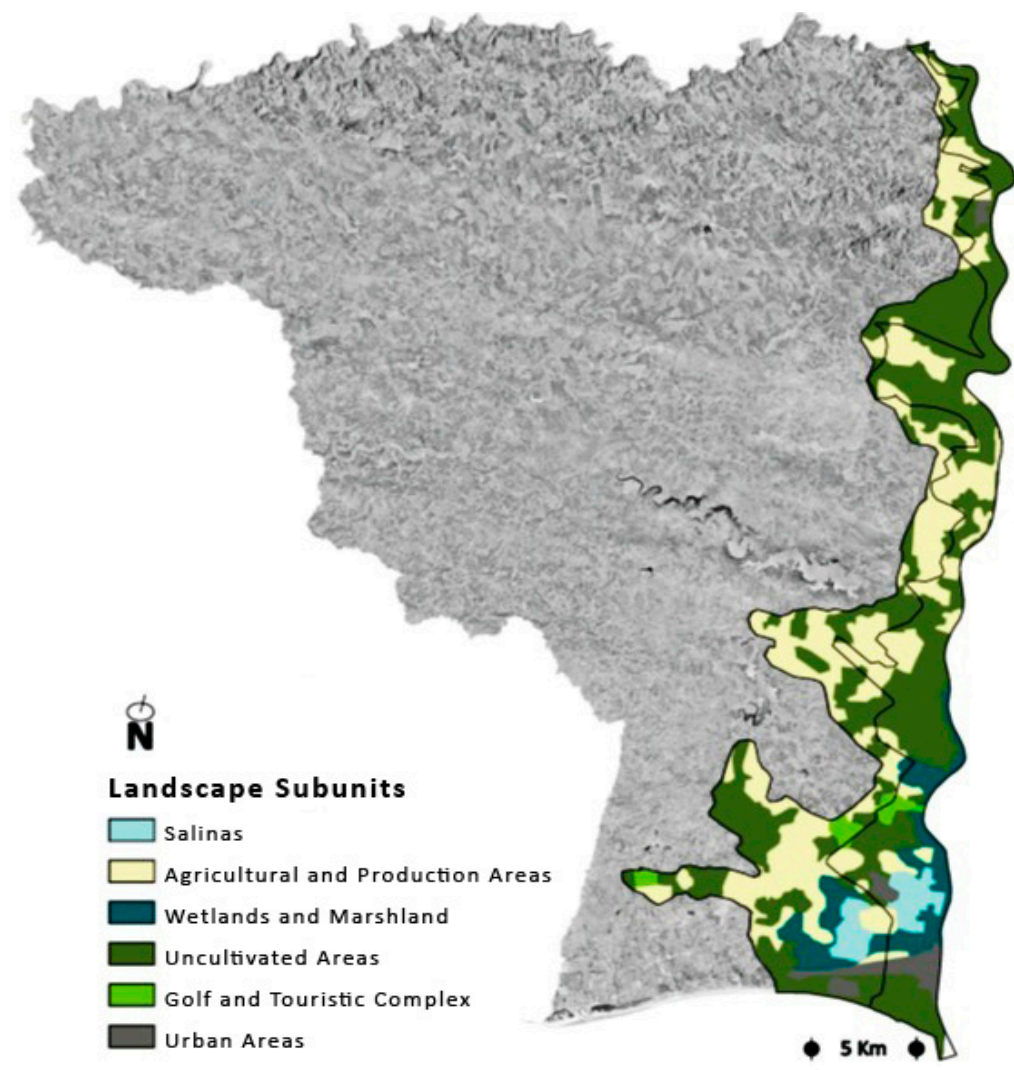

Figure 6. Visual basin and delimitation of landscape subunits.

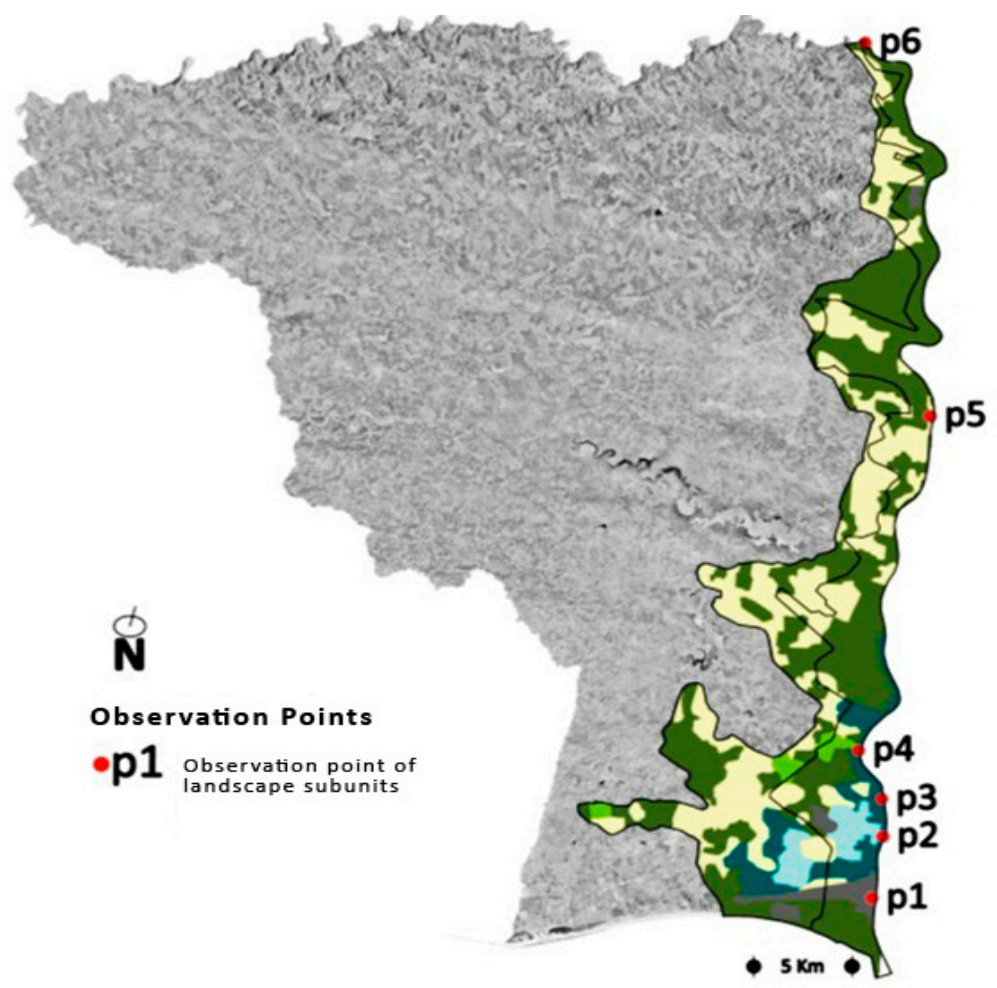

Figure 7. Visual basin, landscape subunits and observation points. 


\section{Results}

Questionnaires were completed between March and May 2011, during which 250 questionnaires were delivered. Of these, 148 questionnaires were returned, resulting in a response rate of 59.20\%. From the respondents, $56.80 \%$ were women, $24.30 \%$ men, and $18.90 \%$ of the respondents did not respond to the gender question. The most represented age group was over 65 years, with $47.30 \% ; 39.20 \%$ were aged between 46 and 65; 6.80\% were aged between 30 and 45 years, and $6.80 \%$ of people did not respond. With regard to the education level, $55.40 \%$ of respondents had primary education, $32.40 \%$ had secondary level; only $4.10 \%$ had a graduation degree, and only $2.70 \%$ were postgraduates. The remaining $5.40 \%$ did not answer the question.

With regard to the descriptive analysis of the data considering public preference of 12 images concerning the six identified landscape subunits (Figure 8), it was found that the subunit Touristic Complex and Golf was the one which got the highest value, with an average of 9.70, where the Touristic Complex and Golf image 1 scored 10.22 and Touristic Complex and Golf image 2 scored 9.18. In the opposite situation lies the subunit Urban areas that scored 3.12; 2.40 for Urban area image 1 and 3.83 for Urban area image 2.

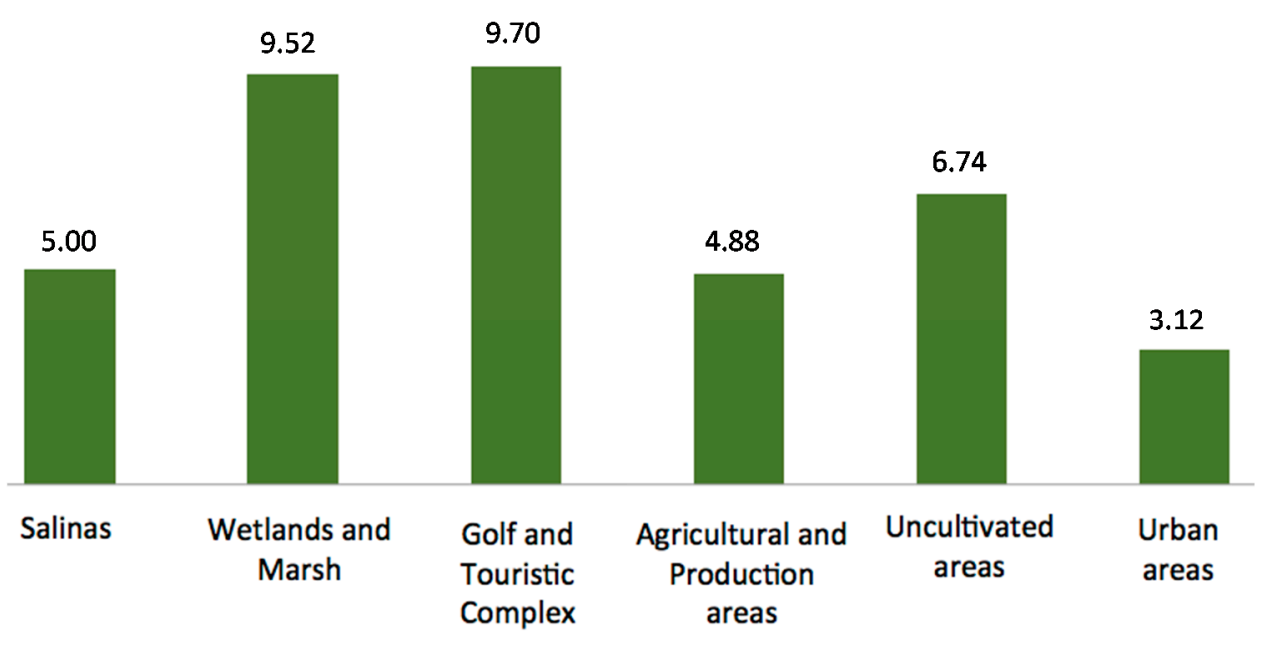

Figure 8. Graphical distribution of public preferences (from 1-12) regarding the identified landscape subunits.

When asked about the quality of the landscape, considering the assigned range-1- Very Low, 2- low, 3- Average, 4- High, and 5- Very High-responses were described by frequency analysis, average and trend. The trend was 3 and the average was 3.75, which, according to the selected classes, ranks as "High". When cross-referencing this data with the characteristics of the sample population (age, gender, education and residence), one could see that the average of 3.75 may be due to the fact that a high percentage of individuals (70) considered the quality of the landscape "High" or "Very High".

With regard to the most relevant landscape parameters considering landscape quality, 23.60\% of respondents felt that the "presence of water" is the most significant parameter in the quality of landscape. On the other hand, mystery was considered the least important factor, selected only by $2 \%$ of respondents. 
When asked about the influence of the urban construction in the degradation of the landscape, most of the respondents $(77 \%)$ considered that urban construction influences negatively the overall landscape quality.

The majority of respondents $(86.50 \%)$ used the bus to get to the study area, since a high percentage of participants were on group visits. As for distance, most of the respondents (54.10\%) travelled between 50 and $300 \mathrm{~km}$. Only a small percentage of respondents $(4.10 \%)$ traveled less than $10 \mathrm{~km}$ to reach the study area. It was also found that the majority of respondents $(39.20 \%)$ took between 1 and 3 hours to arrive to the study area, while $6.80 \%$ of respondents took less than 15 minutes to get there. To visit the study area, most of the respondents $(36.50 \%)$ spent less than $50 €$, however four people $(2.70 \%)$ spent more than $500 €$ (values that will influence the travel-cost analysis performed after).

When asked if they would be willing to pay to visit the study area, $77.03 \%$ of respondents were willing to pay in order to maintain this landscape as it is, so that they could revisit it in the future.

Regarding the aesthetic analysis performed, with the cooperation of the invited specialists, it was possible to ascertain that, considering VQA, Urban areas and Wetlands/Marshland and Salinas subunits have an Average VQA, while the remaining subunits (Tourist Complex/Golf; Agricultural/Production areas and Uncultivated areas) have a Moderate VQA.

In regard to LVF, only the subunit Agricultural/Production Areas presents a high value. All the other subunits have an Average LVF.

Considering VAC, the Tourist Complex/Golf landscape subunit is the one with the highest VAC value, corresponding to a high capacity to absorb changes in the landscape. The Uncultivated areas landscape subunit presents a low VAC. All other subunits have an average VAC.

\section{Conclusions}

Taking into account the objectives of this research and the premise used as a starting point, the application of direct and indirect methods of landscape evaluation allowed us to measure not only the aesthetic and visual qualities of a particular environmental amenity, but also made it possible to attribute market value to certain environmental amenities. The analysis considering both the public participation questionnaire and the landscape assessment by specialists allowed us to obtain some relevant data, namely that:

- The results obtained for the subunit agricultural and production areas corroborate with the conclusions drawn by Panagopoulos [10], according to which the organization of agricultural production landscapes tends to be associated with a low aesthetic quality;

- Although marshes are considered as one of the richest ecosystems in environmental and ecological perspectives, it appears that, regarding landscape visual quality, this ecosystem/landscape subunit is characterized by low values, when compared to other landscape subunits considered in the present study;

- Though the subunit Touristic Complex and Golf obtained the highest result considering respondents' preferences, the fact that the "Presence of Water" parameter was considered as the most relevant to landscape quality might have influenced the results; 
- While about half of the respondents agree that the construction developments along the riverbanks contribute to the degradation of landscape quality, it appears that the touristic complex and golf subunit, which corresponds to the various buildings associated with tourism developments, was the one that obtained a higher preference;

- Although it is considered important that each visitor spent on average about 50 Euros to visit this landscape, it should be noted that this value may be overinflated considering the assumptions made by Seling and Spathelf [20], according to which the money spent in certain trips cannot be exclusively attributed to a specific component of the trip. Furthermore, the importance of this landscape at regional, national and international levels is supported by the analysis of the residence areas of each of the respondents/boat users, since approximately $70 \%$ had to travel more than 50 kilometers to visit this landscape.

With regard to the comparative analysis of landscape quality, considering on the one hand the data obtained through the public participation questionnaire filled out by visitors/boat users, and on the other, the data obtained throughout the analysis on landscape quality and fragility and on visual absorption capacity, developed by experts, it is concluded that there are significant differences. According to the opinions expressed by experts, the overall landscape quality of the study area considering a scale ranging from $1-5$ (where 1 corresponds to the lower quality and 5 the highest quality) is 2.22 -average quality, a classification considerably lower than the value obtained through public participation analysis. Considering the same scale, visitors considered that landscape to have a moderate-high quality, attributing it 3.75 out of 5 .

Although we cannot objectively indicate the reasons responsible for the highlighted differences, these may be due to two different factors. On the one hand, factors inherent to the application and intrinsic characteristics of the used method, and on the other hand due to the analytical parameters considered on the expert analysis and their weight as determinants of landscape quality. Still, the obtained results show that landscape design and management should not be solely based on expert opinion since there are considerable differences between the general public's and experts' opinions. In this regard, landscape evaluation processes should, whenever possible, enhance the joint implementation of various levels of analysis, since it allows us to obtain more objective data regarding a particular environmental good/service than would regular, independent aesthetic analysis.

Moreover, it can be concluded that the application of public participation questionnaires increases the sense of social responsibility of the population, playing a key role in sustainable development and in future landscape planning, since it allows the acquisition of relevant information not only regarding landscape features but also considering public preference of landscape characteristics. For example, it was found that although golf tourist complexes are generally a target of criticism, both from aesthetic and environmental standpoints, the representative images of this landscape subunit were the ones with a greater aesthetic quality score and were considered as an aspect of attractiveness to the increasingly desertified area.

In addition to the data obtained, this research indicates that the study area is worthy of special attention in terms of policy, since it can contribute to an effective improvement in quality of life. Additionally, the present research corroborates with noteworthy ideas put forward in recent studies [35], according to 
which the application of direct and indirect landscape assessment methods enables the acquisition of valuable information for landscape planning and management.

\section{Acknowledgments}

The authors would like to acknowledge financial support given by the Centre for Spatial and Organizational Dynamics (CIEO) and from the Foundation for Science and Technology (FCT).

\section{Author contributions}

Ana Loures, Luis Loures and Thomas Panagopoulos design the research and performed the analysis; Ana Loures, Luis Loures and José Rato Nunes wrote the paper. Luis Loures and Thomas Panagopoulos made the final revision of the paper and answer to the reviews questions.

\section{Conflicts of Interest}

The authors declare no conflict of interest.

\section{References}

1. Loures, L. Revitalização das Aldeias do Algarve. In Trabalho Final de Curso; Universidade do Algarve: Faro, Portugal, 2005.

2. Telles, G. A Paisagem é Tudo. Pessoas e Lugares. Available online: http://www.leader.pt/pt.lugares/ jornalp116.pdf (accessed on 10 December 2011).

3. Lothian, A. Landscape and the philosophy of aesthetics: Is landscape quality inherent in the landscape or in the eye of the beholder? Landsc. Urban Plan. 1999, 44, 177-198.

4. Galofaro, L. Artscapes-Art as an Approach to Contemporary Landscape; Editorial Gustavo Gili: Barcelona, Spain, 2003.

5. Vaz, E.; Bowman, L. An application for regional coastal erosion processes in urban areas: A case study of the Golden Horseshoe in Canada. Land 2013, 2, 595-608.

6. Vaz, E.; Walczynska, A.; Nijkamp, P. Regional challenges in tourist wetland systems: An integrated approach to the Ria Formosa in the Algarve, Portugal. Reg. Environ. Chang. 2013, 13, 33-42.

7. Steiner, F. The Living Landscape: An Ecological Approach to Landscape Planning, 2nd ed.; McGraw-Hill: New York, NY, USA, 2000.

8. Steinitz, C. A framework for theory and practice in landscape planning. Ekitics 1994, 61, 364-365.

9. Langhorst, J. Rising from Ruins: Post-industrial Sites between Abandonment and Engagement. In Proceedings of the Open Space: People Space Conference, Edinburgh, Scotland, 27-29 October 2004.

10. Panagopoulos, T. Linking forestry, sustainability and aesthetics. Ecol. Econ. 2009, 68, 2485-2489.

11. Mayoh, J.; Onwuegbuzie, A.J. Toward a conceptualization of mixed methods phenomenological research. J. Mixed Methods Res. 2015, 9, 91-107.

12. Arthur, L.; Daniel, T.; Boster, R. Scenic assessment: An overview. Landsc. Plan. 1977, 4, 109-129.

13. Canter, L. Environmental Impact Assessment; McGraw-Hill International Editions: Singapore, 1996. 
14. Ayala, R.; Ramirez, J.; Camargo, S. Valoración de la calidad y fragilidad visual del paisage en el Valle de Zapotitlán de las salinas, Puebla (México); Faculdade de Geografia e Historia da Universidade de Madrid: Madrid, Spain, 2003.

15. Burley, J. Environmental Design for Reclaiming Surface Mines; The Edwin Mellen Press: New York, NY, USA, 2001.

16. Vargues, P.; Loures, L. Using Geographic Information Systems in visual and aesthetic analysis: The case study of a golf course in Algarve. WSEAS Trans. Environ. Dev. 2008, 4, 774-783.

17. Mazure, A.; Burley, J.B. An aesthetic, economic, and ecological equation/theories for predicting environmental quality: Including a GIS-based remote access application. In Our Shared Landscape: Integrating Ecological, Socio-economic and Aesthetics Aspects in Landscape Planning and Management; Lange, E., Miller, D., Eds.; Swiss Federal Institute of Technology: Ascona, Switzerland, 2005; pp. 68-69.

18. Leite, D.; Jacoski, C. Comportamento do usuário na valoração contingente e custo de viagem-O parque das palmeiras em Chapecó, SC, Brasil. Rev. Amb. Água 2010, 5, 226-235.

19. Oesten, G. Zur Wertschätzung der Infrastrukturleistungen des Pfälzerwaldes; Forstlichen Versuchsanstalt Rheinland-Pfalz: Trippstadt, Germany, 1994; p. 156.

20. Seling, I.; Spathelf, P. Benefícios indiretos da floresta. Rev. Ciênc. Florest. 1999, 9, 137-146.

21. Varian, H. Microeconomia; Princípios, B., Ed.; Campus: Rio de Janeiro, Brazil, 2003.

22. Birol, E.; Karousakis, K.; Koundouri, P. Using economic valuation techniques to inform water resources management: A survey and critical appraisal of available techniques and an application. Sci. Total Environ. 2006, 365, 105-122.

23. Nijkamp, P.; Vindigni, G.; Nunes, P.A. Economic valuation of biodiversity: A comparative study. Ecol. Econ. 2008, 67, 217-231.

24. Matias, R.C.; Panagopoulos, T. The impact of limestone quarrying in Algarve Portugal. In Proceedings of the 9th International Conference on Environmental Science and Technology, Rhodes, Greece, 1-3 September 2005; Lekkas, T.D., Ed.; pp. 574-579.

25. Panagopoulos, T.; Vargues, P.M. Visual impact assessment of a golf course in a Mediterranean forest landscape. In Patterns and Processes in Forest Landscapes, Consequences of Human Management; Lafortortezza, L., Sanesi, G., Eds.; Accademia Italiana di Scienze Florestali: Firenze, Italy, 2006; pp. 279-285.

26. Ramos, B.; Panagopoulos, T. Integrating aesthetics in visual impact assessment and quarry reclamation project. WSEAS Trans. Environ. Dev. 2006, 2, 506-511.

27. Panagopoulos, T.; Matias, R.; Ramos, B. Visual impact and reclamation of limestone quarries in Algarve Portugal. In Thirty Years of Surface Mine Control and Reclamation Act and Beyond; Barnhisel, R.I., Ed.; American Society of Mining and Reclamation: Lexington, KY, USA, 2007; pp. 611-617.

28. Berte, E.; Panagopoulos, T.; Zannon, B. An interpretative model for the management of contemporary cultural landscapes in linear infrastructure projects. J. Environ. Eng. Landsc. Manag. 2013, 21, 248-262.

29. Loures, L.; Vargues, P.; Horta, D. Landscape aesthetical and visual analysis facing the challenge of the development of sustainable landscapes - The case study of the post-industrial area to the left margin of the Arade River. Int. J. Des. Nat. Ecodyn. 2008, 3, 65-74. 
30. Burley, J.; Singhal, V.; Burley, C.; Fassier, D.; Churchward, C.; Hellekson, D.; Raharizafy, I. Citation analysis of transportation research literature: A multi-dimensional map of the roadside universe. Landsc. Res. 2009, 34, 481-495.

31. Loures, L. Planning and Design in Postindustrial Land Transformation: East Bank Arade River, Lagoa. Ph.D. Thesis, Faculty of Science and Technology, University of Algarve, Faro, Portugal, 2010.

32. Faria, S.; Godinho, M.A.; Machado, M. Estudo Hidroclimatológico da Região do Algarve: O Clima de Portugal; Instituto Nacional de Meteorologia e Geofísica: Lisboa, Portugal, 1981.

33. Berte, E.; Panagopoulos, T. Enhancing city resilience to climate change by means of ecosystem services improvement: A SWOT analysis for the city of Faro, Portugal. Int. J. Urban Sustain. Dev. 2014, 6, 241-253.

34. Abreu, A.; Correia, T.; Oliveira, R. Contributos para a Identificação e Caracterização da Paisagem em Portugal Continental; Colecção Estudos 10; Universidade de Évora, Direcção Geral do Ordenamento do Território e Desenvolvimento Urbano: Lisboa, Portugal, 2004.

35. Casado-Arzuaga, I.; Onaindia, M.; Madariaga, I.; Verburg, P. Mapping recreation and aesthetic value of ecosystems in the Bilbao Metropolitan Greenbelt (northern Spain) to support landscape planning. Landsc. Ecol. 2014, 29, 1393-1405.

(C) 2015 by the authors; licensee MDPI, Basel, Switzerland. This article is an open access article distributed under the terms and conditions of the Creative Commons Attribution license (http://creativecommons.org/licenses/by/4.0/). 